\title{
Critical role of CCDC6 in the neoplastic growth of testicular germ cell tumors
}

Stefania Staibano ${ }^{3}$, Gennaro llardi ${ }^{3}$, Vincenza Leone ${ }^{1}$, Chiara Luise ${ }^{1}$, Francesco Merolla ${ }^{1,3}$, Francesco Esposito', Francesco Morra', Maria Siano ${ }^{3}$, Renato Franco ${ }^{4}$, Alfredo Fusco ${ }^{1,2}$, Paolo Chieffi ${ }^{5}$ and Angela Celettr

\section{Abstract}

Background: DNA damage response has been clearly described as an anti-cancer banter in rly human tumorigenesis. Moreover, interestingly, testicular germ cell tumors (TGCTs) have bef sported, $\sigma$ lack the DNA Damage Response (DDR) pathway activation.

CCDC6 is a pro-apoptotic phosphoprotein substrate of the kinase ataxia telang asia muated (ATM) able to sustain DNA damage checkpoint in response to genotoxic stress and is ch. no rarranged in malignancies upon fusion with different partners.

In our study we sought to determine whether CCDC6 could have a r in the patho-genesis of testicular germ cell tumors.

Methods: To achieve this aim, analysis for CCDC6 expression has been vyluated on serial sections of the mouse testis by immunohistochemistry and on separate populations o urine testicular cells by western blot. Next, the resistance to DNA damage-induced apoptosis and the pro ctio of reactive oxygen species has been investigated in GC1 cells, derived from immortalized type B muri 1e germ Nos, following CCDC6 silencing. Finally, the CCDC6 expression in normal human testicular cells, in Int ub lar Geen Cell Neoplasia Unclassified (IGCNU), in a large series of male germ cell tumours and in the yique man seminoma TCam2 cell line has been evaluated by immunohistochemistry and by Western Blo

Results: The analysis of the CCDC6 exprysion 1 aled its presence in Sertoli cells and in spermatogonial cells. CCDC6 loss was the most consistent reature among the primary tumours and TCam2 cells. Interestingly, following treatment with low doses of $\mathrm{H}_{2} \mathrm{O}_{2}$, $\mathrm{t}$ s silenci'h of CCDC6 in $\mathrm{GC} 1$ cells caused a decrease in the oxidized form of cytochrome $\mathrm{c}$ and low detection of $\mathrm{D} \wedge \mathrm{P}$ P-1 and Caspase 3 proteins. Moreover, in the silenced cells, upon oxidative damage, the cell via was protected, the $\mathrm{\gamma H} 2 \mathrm{AX}$ activation was impaired and the Reactive Oxygen Species (ROS) release was decreasea.

Conclusions: Therefore, $r$ results suggest that the loss of CCDC6 could aid the spermatogonial cells to be part of a pro-survival pathwa, as to evade the toxic effects of endogenous oxidants and contributes to testicular neoplastic grov th.

Keywords: CCDO Testicular germ cells tumours, TMA, DNA damage response, T-CAM2, GC-1, ROS, Oxidative DNA danage

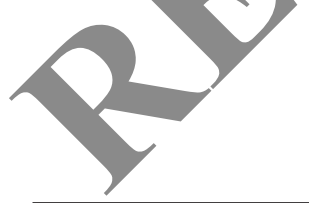

\footnotetext{
*Correspondence: celetti@unina.it

${ }^{1}$ Istituto di Endocrinologia ed Oncologia Sperimentale, CNRz, via S Pansini,

5, Naples 80131, Italy

${ }^{2}$ Dipartimento di Medicina Molecolare e Biotecnologie Mediche, Università

Federico II, Naples, Italy

Full list of author information is available at the end of the article
}

\section{Biomed Central}

(c) 2013 Staibano et al.; licensee BioMed Central Ltd. This is an Open Access article distributed under the terms of the Creative Commons Attribution License (http://creativecommons.org/licenses/by/2.0), which permits unrestricted use, distribution, and reproduction in any medium, provided the original work is properly cited. 


\section{Background}

Testicular germ cell tumours (TGCTs), the most common malignancy in males aged 15-34 years, represent a major cause of death attributable to cancer in this age group $[1,2]$. TGCTs can be subdivided into seminoma and non-seminoma germ cell tumours (NSGCTs), including embryonal cell carcinoma, choriocarcinoma, yolk sac tumour and teratoma. Neoplasms containing more than one tumour cell component, eg seminoma and embryonal cell carcinoma, are referred to as mixed germ cell tumours. Seminomas and NSGCTs present distinctive clinical features with significant differences in prognosis and therapeutic approach [3]. Nevertheless, the molecular alterations and biomarkers of TGCTs still remain poorly defined [4]. Recently, it has been suggested that resistance to oxidative DNA damage is commonly associated to testicular germ cell transformation [5].

The maintenance of the genome integrity and the protection against the harmful mutagenic effects of DNA damage rely on the DNA damage response (DDR) machinery postulated to serve as an inducible barrier against tumorigenic transformation and/or progression for human cancers [6,7]. Notably, testicular germ cell tumours have been shown, so far, to represent an exception among human malignancies tested for constitutive DDR activation in that this phenomenon occurs only rarely [8].

In previous works we have documented the $\ell$. gene product as a pro-apoptotic protein syostrat ATM, able to sustain DNA damage check p ts in re sponse to DNA damage [8-10]. CCDC6 was rinally identified upon rearrangement with PET in thyro, $A$ and lung tumours $[11,12]$, and with gene other than RET in solid and not solid tumours [13-16, most cancers harbouring CCDC6 gene rearra sments, the product of the normal allele is supposed to be ctionally impaired or absent. Fusions inclya CCL C6 or other genes have not been reported in GC so rar (www.sanger.ac.uk/ genetics/CGP/cos $/ 1 \mathrm{c}$ ). vently, the finding that CCDC6 helps to protea nome, tegrity by modulating PP4C activity directed to ards pS139_H2AX dephosphorylation following DNA yamage [11], makes CCDC6 an attractive nuidat that could help pre-cancerous cells ove me DNA damage response-dependent barrier rain tumour progression. Therefore, we hypothesize th wrun CCDC6 is deleted or silenced, the loss of chec Jints and of repair accuracy [17] might favour genome instability and may represent an early independent event of a multistep carcinogenetic process in primary tumours.

The tissue distribution and cell type-related expression patterns of CCDC6 in normal tissue remain largely unknown; on the other hand there are as yet no reports of analyses of CCDC6 in either human or animal tumours.
By the analysis of the Gene Expression Atlas (Array ExpressAtlas), a meta-analysis-based database of the ArrayExpress Archive, we noticed that CCDC6 was predicted as downregulated in germ cell tumours. Here, we intend to gain more insights into the CCDC6 tissue biology and its relation to testicular cancer in order to $y$ ravel a role for CCDC6 as a new DDR component th - participates in genome stability maintenance and wh malfunction may contribute to the pathogenesis of ger tumours.

\section{Methods}

\section{Cell lines and antibodies}

The GC-1 cell line was culturo in Du_cco's modified Eagle's medium (D-ME 1 ) supp nented with $10 \%$ fetal bovine serum (FBS; G'OC RL, Italy) and grown in a $37^{\circ} \mathrm{C}$ humidified atmosphere of $\mathrm{CO} 2$ [18]. TCAM-2 cells were grown at $57^{\circ} \mathrm{O}$ in a 5\% CO2 atmosphere in RPMI 1640 (Lonza) red with 10\% FBS [19]. Anti pS139_H2AX ant dy was from Millipore; Anti-H2AX, anti-pT68 and anti-Chk2 antibodies were from Cell Signaling Tecnnyogy, Inc; anti MDC1 and anti CCDC6 were from Abcam; Anti-Cytochrome c (Biovision Inc, US. anti COX IV (Cell Signaling Technology, Inc); Anti- aspase 3 (H-277) Sc 7148, anti-Bcl 2 (N19) Sc 492, - DARP (H250) Sc 7150, anti-Bad (C20) Sc493 and secondary antibodies were from Santa Cruz Biotechnology, Inc; Anti $\alpha$-tubulin was from Sigma -Aldrich Co. LLC.

\section{Plasmids and transfections}

Mission shRNA (pLKO.1 puro) were from Sigma-Aldrich, Co. LLC.

For transient transfection assays the $\mathrm{GC} 1$ cells were transfected with the plasmid pool (shCCDC6, NM_001111121.1) or a pool of non- targeting vectors (sh control) by the Nucleofector transfection system. pCDNA4TO-CCDC6T434A mutant has been described elsewhere [10]. The Fugene reagent (Roche Ltd, Basel, Switzerland) was used to transfect GC1 cells accordingly to the manufacturer's instructions.

\section{MTT cell proliferation assay}

GC-1 cells were transfected with mission shCCDC6 or a control non-targeting scrambled sh, after $48 \mathrm{~h}$ were treated with $\mathrm{H}_{2} \mathrm{O}_{2}$ at different doses (range of 1, 2, 5 and $10 \mu \mathrm{M}$ ) for $1 \mathrm{~h}$, as indicated. After washing out the hydrogen peroxide we have left the cells an additional hour before processing them. $20 \mathrm{ml}$ of Promega's CellTiter 96 AQueous One Solution (Promega) were then dispensed into each well and absorbance at $595 \mathrm{~nm}$ was measured to evaluate cell viability. Data reported are the average $+/-$ s.d. of three independent experiments performed in sextuplicate. Anti-proliferative assays with a wide range of $\mathrm{H}_{2} \mathrm{O}_{2}$ doses $(1,2,5,10$ and $50 \mu \mathrm{M})$ and at different times (30 min and 
1 hour) in GC1 cells, transiently silenced, (shCCDC6 and shCtrl), are shown in the Additional file 1: Figure S1. Data reported are the average $+/-$ s.d. of three independent experiments performed in sextuplicate.

\section{Apoptosis assays}

GC-1 cells were transfected with mission shCCDC6 or a control non-targeting scrambled sh, after $48 \mathrm{~h}$ this cells were treated with $\mathrm{H}_{2} \mathrm{O}_{2}$ at $10 \mu \mathrm{M}$ for $1 \mathrm{~h}$ and apoptosis was quantified by measuring Caspase $3 / 7$ activation using the Caspase-Glo $3 / 7$ assay (Promega) according to the manufacturer's instructions.

\section{Cytochrome $\mathrm{c}$ releasing apoptosis assay Kit}

GC-1 cells were transfected with mission shCCDC6 or a control non-targeting scrambled sh, after $48 \mathrm{~h}$ of transfection the apoptosis was induced by treatment of cells with $\mathrm{H}_{2} \mathrm{O}_{2}$ at $10 \mu \mathrm{M}$. After $1 \mathrm{~h}$ of $\mathrm{H}_{2} \mathrm{O}_{2}$ treatment, the cytochrome c release was quantified using the Cytochrome $\mathrm{c}$ Releasing Apoptosis Assay Kit (BioVision Inc, USA) according to the manufacturer's instructions.

\section{Preparation of testicular cells}

Germ cells were prepared from testes of adult CD1 mice (Charles River Italia). Testes were freed from the albuginea membrane and digested for $15 \mathrm{~min}$ in $025 \%$ $(w / v)$ collagenase (type IX, Sigma) at room temp tu) under constant shaking. They were then wash a twic minimum essential medium (Life Technor es, Inc. seminiferous tubules were cut into pieces with sterile blade and further digested in minimur essential medium containing $1 \mathrm{mg} / \mathrm{ml}$ trypsin for $30 \mathrm{~m}$ at $30^{\circ} \mathrm{C}$ ) Digestion was stopped by adding $10 \%$ fetal calf s $\mathrm{m}$ ard the germ cells released were collected af cedimentation (10 min at room temperature) of tissue de $\omega_{\text {G }}$ Germ cells were centrifuged for $13 \mathrm{~min}-1500$ r.p.m. at $48^{\circ} \mathrm{C}$ and the pellet resuspended in $\mathrm{m}$ folytriation medium (120.1 $\mathrm{mM} \mathrm{NaCl}, 4.8 \mathrm{ma}$ K $25.2 \mathrm{mM} \mathrm{NaHCO} 3,1.2 \mathrm{mM}$ MgS4 (7H2O) $2 \mathrm{mM}$ ) ácl2, $1.1 \mathrm{mM}$ glucose, $1 \mathrm{X}$ essential amino ac (Life Technologies, Inc.), penicillin, streptom cin, 0.5\% bvine serum albumin). Pachytene spermat and spermatid germ cells were obtained by elv tion the unfractionated single cell suspension. ome reneity of cell populations ranged between 80 and 8. (pacriytene spermatocytes) and 95\% (spermatids), was tinely monitored morphologically. Spermatogonia were obtained from prepuberal mice as previously described [20]. Mature spermatozoa were obtained from the cauda of the epididymis of mature mice as described previously [21].

\section{TMA building}

According to ethical guidelines, Tissue Micro-Array (TMA) was built using the most representative areas from each single case. All tumours and controls were reviewed by two experienced pathologists. Discrepancies between two pathologists from the same case were resolved in a joint analysis of the cases. Tissue cylinders with a diameter of $0.3 \mathrm{~mm}$ were punched from morphologically representative tissue areas of each 'donor' 'issue block and brought into one recipient paraff $n$ block $(3 \times 2.5 \mathrm{~cm})$ using a semiautomated tissue arrayer allieo TMA, Milan, Italy).

\section{Histological analysis and immunohistochem}

For light microscopy, tissues were fixed by im mersion in $10 \%$ formalin and embedded in pa ffin by standard procedures; $4 \mu \mathrm{m}$ sections were aint $x$ h haematoxylin and eosin (H\&E) or proc ssed fo, nmunohistochemistry. The classical avidin- 010 peroxadase complex (ABC) procedure was used for im nohistochemistry. The sections were incroat overnight with antibodies against CCDC6 at 1. 1. The following controls were performed: (a) om in of the primary antibody; (b) substitution he primary antiserum with non-immune serum diluler 1:, 000 in blocking buffer; (c) addition of the target pepticle used to produce the antibody $\left(10^{-6} \mathrm{M}\right)$; no im nostaining was observed after any of the control roce ures. The antibody against the CCDC6 proteins is I. njigma-Aldrich, Co. LLC. (HPA-019051).

\section{Protein extraction and western blot analysis}

Total cell extracts (TCE) were prepared with lysis buffer (50 mM Tris- $\mathrm{HCl} \mathrm{pH} 7.5,150 \mathrm{mM} \mathrm{NaCl}, 1 \%$ Triton X-100, 0.5\% Na Deoxycholate, 0.1\% SDS) and a mix of protease inhibitors. Protein concentration was estimated by a modified Bradford assay (Bio-Rad). Total proteins were prepared as described [22]. Membranes were blocked with 5\% TBS-BSA proteins and incubated with the primary antibodies. Immunoblotting experiments were carried out according to standard procedures and visualized using the ECL chemiluminescence system (Amersham/Pharmacia Biotech). As a control for equal loading of protein lysates, the blotted proteins were probed with antibody against anti- $\gamma$-tubulin protein.

\section{Real time PCR}

Total RNA was isolated using TRI-reagent solution (Sigma) according to the manufacturer's instructions and treated with DNase I (GenHunter Corporation, Nashville, TN, U.S.A.). RNA $(1 \mu \mathrm{g})$ was reverse-transcribed using a mixture of poly-dT and random exonucleotides as primers and MuLV RT (PerkinElmer, Boston, MA, U.S.A.). PCR reverse transcription was performed according to standard procedures (Qiagen). qRT-PCR analysis was performed using the follows primers annealing at CCDC6 aminoterminus: Fw: ggagaaagaaacccttgctg and Rv: tcttcatcagtttg ttgacctga. To calculate the relative expression levels we 
used the $2-\Delta \Delta C T$ method. Primers for Beta-actin were used for normalization of qRT-PCR data [23].

\section{Fluorometric determination of Reactive Oxygen Species (ROS)}

The production of ROS was measured using the 5,6-carboxy-2'-7' -dichlorofluorescein-diacetate, DCFH-DA, fluorometric method, which is based on the ROSdependent oxidation of DCFH-DA to DCF (Molecular Probes, The Netherlans). Control and transfected GC1 cells, after $\mathrm{H}_{2} \mathrm{O}_{2}$ exposure where indicated, were treated with DCFH-DA $(20 \mu \mathrm{M})$ for $30 \mathrm{~min}$ at $37^{\circ} \mathrm{C}$ in the dark. Intracellular ROS production was measured with a spectrofluorometer (SFM 25; Kontron Instruments, Japan). A positive control was obtained by incubating GC1 cells with $\mathrm{H}_{2} \mathrm{O}_{2}$ at $10 \mu \mathrm{M}$ for 1 hour.

\section{Results}

\section{CCDC6 expression in mouse testicular cells}

In order to define the cells in which CCDC6 is expressed in the normal testis, immunohistochemical analysis for this protein was performed on serial sections of the mouse testis. The CCDC6 protein was widely expressed in the germinal epithelium, mostly in the spermatogonlal cells found at the basal compartment of the semin. ol epithelium, where they adhere to the basem -110 m brane, while less so in the spermatocytes an a srmatidy The Sertoli cells, essential componentr of $t_{1}$ niche where they physically support the $s$ ermatogonia, cells and provide them with growth factc , also expressed a good amount of the CCDC6 gene prod while it was not detectable in the spermatozoa (h re 1A). Importantly, we checked that the antiserum used in un study fulfilled the criteria of specificity. artictlar, immunoadsorption tests revealed that $t$ la lino was totally blocked by preincubation of than. dy with $10^{-6} \mathrm{M}$ of the cognate peptide (data no own).

Next, we confi od the differential expression of CCDC6 an the differ nt cell types in the mouse testis, by Wes Blct analysis of cell extracts from the adv mou testis fractionated in interstitial, Sertoli, ern atogona, spermatocytes, spermatids and sperma a. mimunoblot analysis performed on cell types enrlo $d$ in the different types of germ cells showed a single product migrating as a $65 \mathrm{kDa}$ protein (Figure 1B). Among germ cells, CCDC6 was well expressed in the spermatogonia, less abundant in the spermatocytes and spermatids and absent in the spermatozoa (Figure 1B), in agreement with the immunohistochemical results. Moreover, the CCDC6 protein was present in the interstitial, at low levels, and the Sertoli extract cells (Figure 1B).
(A)

CCDC6

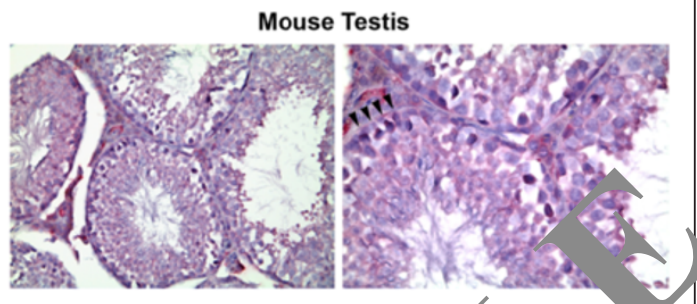

(B)

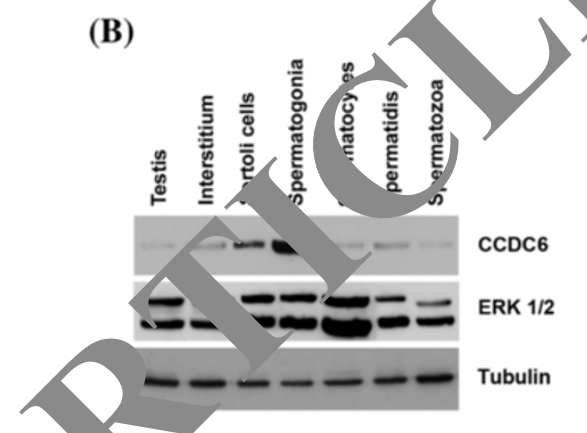

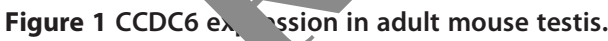

(A) Immu bistochem, staining for CCDC6 protein in adult mouse test 5 (s) a representative seminiferous tubule showing staning it the basal germ cells (arrow heads), Sertoli cells and Leydig Cells, (B) Distribution of CCDC6 protein in mouse ular cells. Western blot analysis of CCDC6 protein in mouse adur stis (lane 1), interstitium (lane 2), Sertoli cells (lane 3) and mouse germ cells (lanes 4-7) (40 $\mu \mathrm{g} / \mathrm{lane})$. Whole lysates detected by western blotting with anti-CCDC6 polyclonal serum or with anti-ERK1 antibodies used as an internal standard. ERK1 antibodies recognize both ERK1 and ERK2, which are expressed at similar levels in all cell types with the exception of spermatozoa. Anti-tubulin hybridization is shown as loading control.

CCDC6 silencing in the GC-1 spermatogonia increases the resistance to peroxide-induced apoptosis

We have previously reported that CCDC6 overexpression is able to induce apoptosis [9]. Conversely, we have shown that several CCDC6 mutants or CCDC6 depletion protected cell viability from multiple and diverse apoptotic stimuli $[9,10]$. Recently, it has been reported that primary testicular germ cells are prone to apoptosis at very low concentrations of $\mathrm{H}_{2} \mathrm{O}_{2}$ [24]. Next, we investigated CCDC6 expression in the GC1 cells, derived from immortalized type $\mathrm{B}$ murine germ cells that were found to express good levels of CCDC6 (Figure 2A, right). In order to investigate if the loss of CCDC6 could affect hydrogen peroxide-induced apoptosis in CCDC6-expressing primordial GC1 cells, we silenced its expression by the transient transfection of specific shRNAs directed against murine CCDC6 and exposed the cells to different doses of hydrogen peroxide for 1 hour (Figure 2A, right). We observed a reversion of an antiproliferative effects following hydrogen peroxide exposure in CCDC6 silenced- compared to control GC1 cells. (Figure 2A, left). Pro-apoptotic stimuli, like reactive oxygen species (ROS), are able to activate the 
A
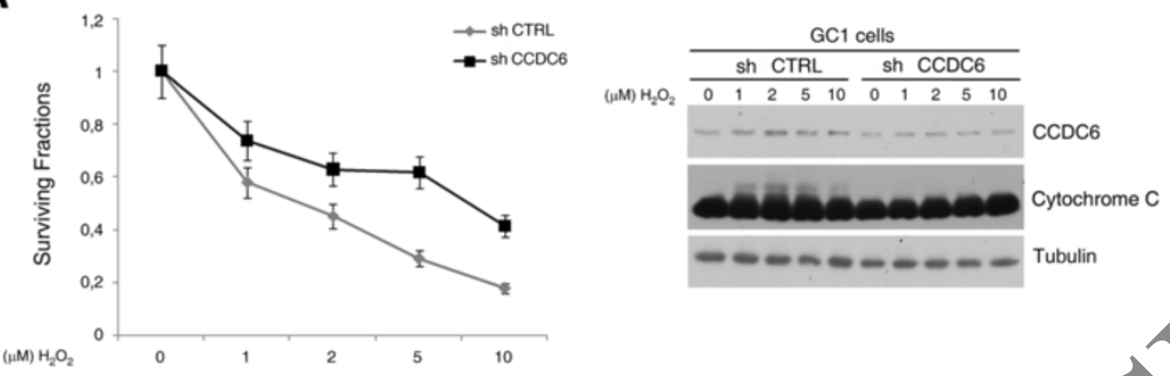

B

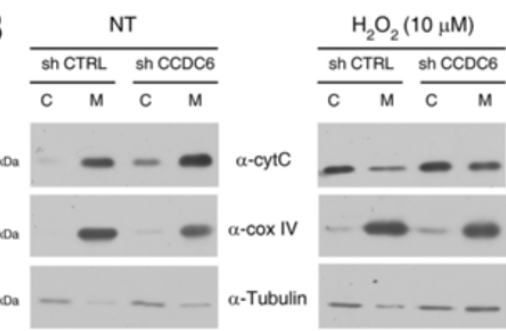

C $\frac{\text { GC1 cells }}{\frac{\text { sh CTRL }}{\text { C }} \frac{\text { sh CCDC6 }}{0} \mathrm{H}_{2} \mathrm{O}_{2}}$
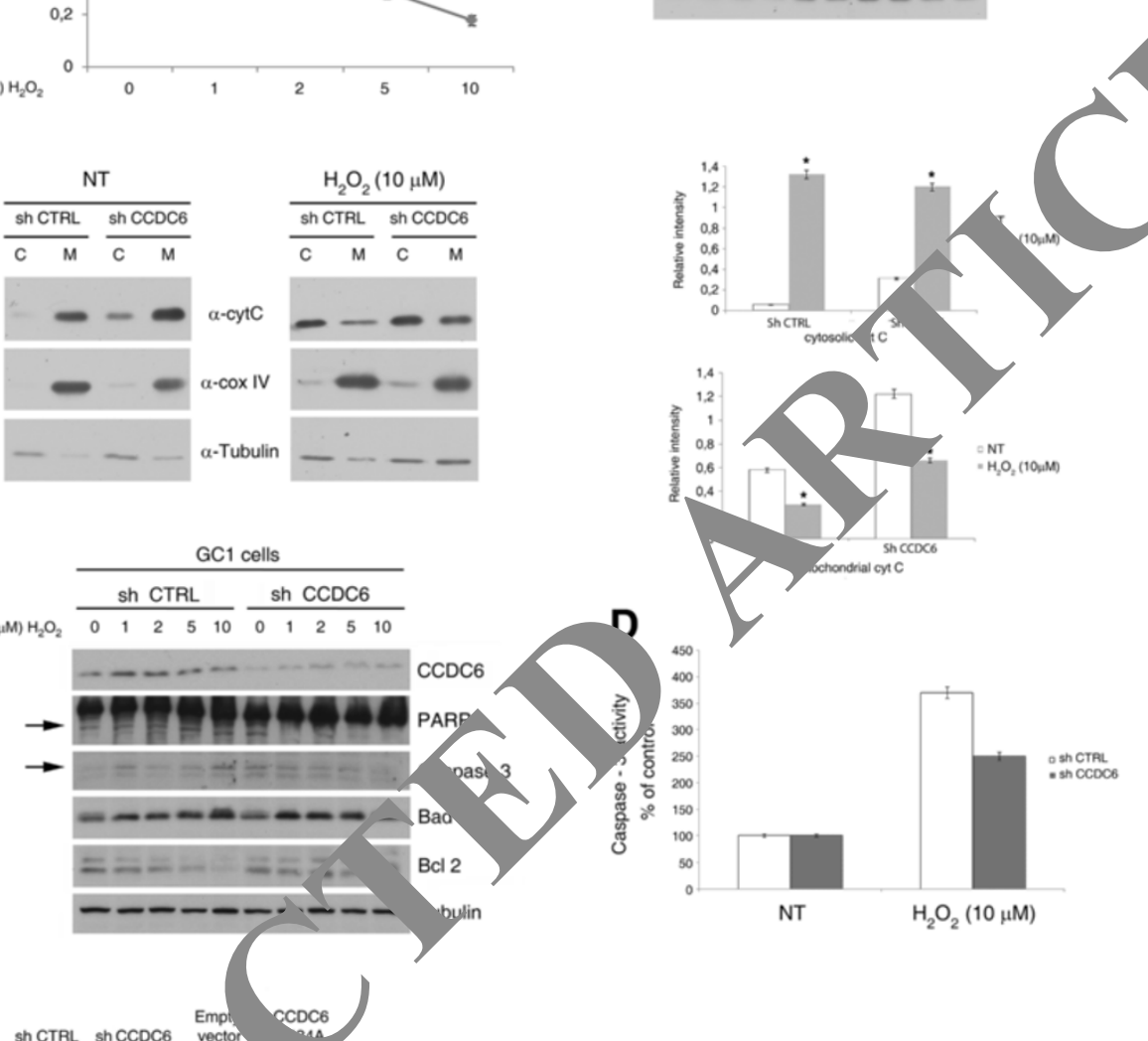

$=\mathrm{HT}_{2} \mathrm{O}_{2}(10, \mathrm{MM})$
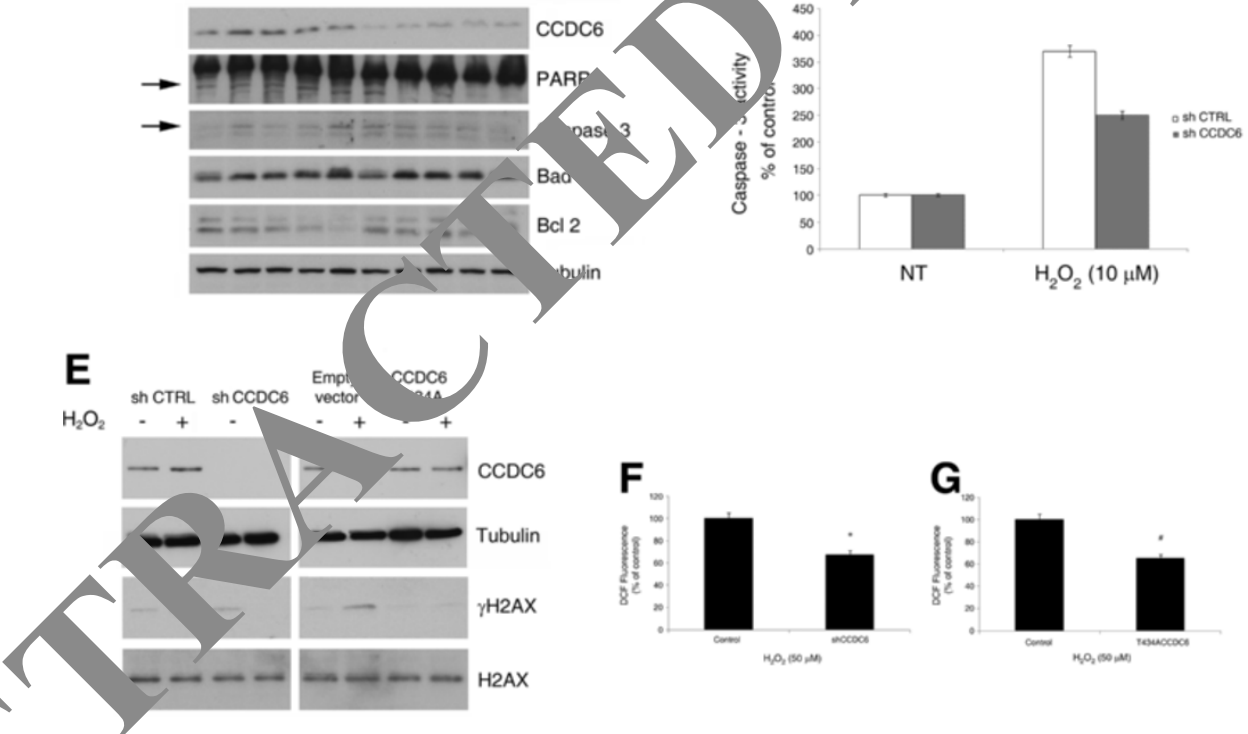

Figure Per vide) sensitivity in CCDC6 silenced GC1 cells. (A) Left side: percentage of cell viability evaluated by MTT analysis on GC1 shCCDC6 $\mathrm{ctrl}$. Ells not treated or treated for 1 hour with H2O2. Right side: CCDC6 and Cytochrome $\mathrm{C}$ immunoblots of GC1 shCCDC or sh ati Is, not red or treated with H2O2. (B) Protein extracts from cytosol (C) and mitochondria (M) of shctrl and shCCDC6 cells untreated or reate inith $\mathrm{H} / 2 \mathrm{O} 2$ as indicated were assayed for Cytochrome $\mathrm{c}$ by western blot analysis. Tubulin was used as cytosolic marker and COX IV as a rchomaral marker. Densitometric acquisition are shown from three separate experiments. ${ }^{*} p>0,05$ vs untreated shCTRL and shCCDC6 cells (C) analysis from GC1 shCCDC6 or sh ctrl lysates from cells not treated or treated with $\mathrm{H} 2 \mathrm{O} 2$. The blots are representative of three inderendent experiments. (D) Caspase 3 activity was evaluated in GC1 cells, shCCDC6 or sh ctrl, not treated or treated with H2O2. The plotted values represent the mean +/- s.e.m. of three independent experiments. (E) Whole cell lysates from GC1 shCCDC6 or sh ctrl cells, and from GC1 cells overexpressing CCDC6T434A or the empty vector, treated with $\mathrm{H} 2 \mathrm{O} 2(10 \mu \mathrm{M})$ or untreated were immunoblotted with anti-CCDC6 or antimyc. Anti- $\gamma \mathrm{H} 2 \mathrm{AX}$ and total H2AX are shown. (F) GC1 cells, depleted or not depleted for CCDC6, were exposed to $50 \mu \mathrm{M}$ H2O2 for 30 minutes and ROS intracellular levels were evaluated by the DCFH-DA fluorometric method. (G) GC1 cells overexpressing CCDC6T434A or the empty vector were exposed to $50 \mu \mathrm{M} \mathrm{H} 2 \mathrm{O} 2$ for 30 minutes and ROS intracellular levels were evaluated by the DCFH-DA fluorometric method. In $\mathbf{F}$ and $\mathbf{G}$ data are representative of three separate experiments. \# $p>0.05$ vs control. Immunoblot of anti-tubulin is shown in $\mathbf{A}, \mathbf{C}$ and $\mathbf{E}$. 
intrinsic pathway of apoptosis by inducing mitochondrial membrane permeabilization and the release of cytochrome $\mathrm{c}$ in the cytosol [25]. Indeed, by western blot analysis, we observed that the oxidized form of cytochrome $\mathrm{c}$ was significantly decreased in GC1-shCCDC6, compared to controls (Figure 2A, right). Furthermore, we performed the Cytochrome $\mathrm{C}$ Releasing Apoptosis Assay that we show in Figure 2B. By this assay we found that 48 hours after the transient silencing of shCCDC6 and ShCTRL in $\mathrm{GC} 1$ cells the cytochrome c release in the cytosol of the GC1 shCCDC6 cells showed a slightly increase, compared to the significant high levels detected in the shCTRL GC1 cells, following one hour exposure to $10 \mu \mathrm{M} \mathrm{H} 2 \mathrm{O} 2$, after washing out the hydrogen peroxide and leaving the cells an additional hour before the lysis. The same filters were reprobed with a monoclonal antibody against cytochrome oxidase subunit IV (COX IV) which is a mitochondrial marker, and then with the anti-tubulin antibody, which is a cytosolic marker. The absence of COX IV in the cytosolic samples confirmed the absence of mitochondrial contamination in the cytosolic fractions (Figure 2B, left). Finally we sorted out the relative intensity of the cytochrome $\mathrm{c}$ in the cytosolic and mitochondrial fractions normalized against the tubulin and the COX IV markers, respectively, in shctrl and in sh CCDC6 GC1 cells, by densitometric analyses of three independent experiments (Figure 2B, right).

To determine whether the $\mathrm{H}_{2} \mathrm{O}_{2}$-induced res. im ance and the subsequent GC1 cell apoptosic re assoc. ated with changes in pro- and anti-apoptotio pro. $\mathrm{s}$, the expression of these proteins was analy ed by wester 1 blot. Bad protein showed lower levels in he GC1)shCCDC6 transfected cells compared to the sh trol transfected cells, after 1 hour treatment wi $10 \mu \mathrm{M} \mathrm{H}_{2} \mathrm{O}_{2}$. The antiapoptotic $\mathrm{Bcl} 2$ protein levels we a d to be increased after $10 \mu \mathrm{M}$ hydrogen $\mathrm{p}$ ide treatment in the CCDC6depleted GC1 cells, np nd to the CCDC6-proficient cells. In addition, we obs ved that the levels of Caspase 3 and of the cle? PARP- 1 proteins were reduced in the CCDC6-silenced co compared to the controls. In these experiments, the effec,s were more evident at $10 \mu \mathrm{M}$ than at 1,2 effi-ncy $\mathrm{O}$ - he ransient silencing (Figure 2C; Additional (1e 2: igure s2). To investigate whether CCDC6 silencing w. TDIe $w$ confer protection by $\mathrm{H}_{2} \mathrm{O}_{2}$ induced apoptosis in te cular germ cells, we studied caspase -3 activity. We found that caspase -3 activity was reduced in shCCDC6 compared to shCTRL GC1 cells, upon $10 \mu \mathrm{M} \mathrm{H}_{2} \mathrm{O}_{2}$ treatment for 1 hour (Figure 2D).

\section{CCDC6 silencing in the GC-1 germ cells decreases reactive oxygen species production}

We reported that stable CCDC6 depletion in HeLa cells affected the phosphorylation of histone H2AX on S139, upon IR and etoposide exposure [11]. In the same cells, CCDC6 silencing affects the levels of histone H2AX phosphorylation, upon $\mathrm{H}_{2} \mathrm{O}_{2}$ treatment (data not shown). Interestingly, in the stable CCDC6-interfered HeLa cells, the re-expression of the wild type protein but not of the CCDC6 protein mutated in the T434A residue, an ATM kinase phosphorylation target, restored $\mathrm{pS} 129 \mathrm{H} 2 \mathrm{AX}$ levels in response to genotoxic stress [11]. Indee so in the GC1 cells, the transient silencing of CCDC6 imp $\mathrm{d}$ pS139_H2AX detection upon low doses $\mathrm{H} 2 \mathrm{O}$ t treatment, compared to control cells (Figard 2E). Tot oly, the overexpression of the CCDC6 $\mathrm{T}$ 34A mutar, that behaved as a dominant negative of $t$ wild type protein, affected the phosphorylation sta of nistone H2AX in the absence or presence of $\mathrm{H}_{2} \mathrm{O}$ in comparison to the empty vector transfectea 'ls (Figure 2E). These observations therefore suggested th the recognition site for the ATM kinase in CCD 6 was also important in response to DNA damage 10 oxidative stress. By immunoblot analysis of $\mathrm{CCDC}$, recould also observe that the protein was stabil in response to $\mathrm{H}_{2} \mathrm{O}_{2}$ in the sh-ctrl and in the empty rector transfected GC-1 cells, compared to the T434A over expressing cells, where the $\mathrm{H}_{2} \mathrm{O}_{2}$ treatments dia t stabilize the CCDC6 protein (Figure 2E). As a conrol, 1 the lanes where CCDC6 was silenced in the GC1 c $\left.-1+\mathrm{H}_{2} \mathrm{O}_{2}\right)$, the anti-CCDC6 hybridization allows a venfication of the efficiency of the silencing (Figure 2E). Overall, these experiments have showed that, in the GC1 cells, the loss of CCDC6 or its functional impairment by mutation of a single residue limited the amount of S139_pH2AX that then influenced the sensing of DNA damage induced by $\mathrm{H}_{2} \mathrm{O}_{2}$, relative to the control cells.

Finally, to evaluate whether an altered redox state could be responsible for the pro-survival effects observed when CCDC6 is depleted, we measured the intracellular levels of $\mathrm{ROS}$, in response to $\mathrm{H}_{2} \mathrm{O}_{2}$ exposure. In the $\mathrm{GC} 1$ cells the transient silencing of CCDC6 produced lower levels of ROS, compared to control ("p $\leq 0.05$ ) (Figure $2 \mathrm{~F}$ ), as judged by the fluorescence signal detection following the interaction between the DCFH-DA probe and ROS. In the same cells, the transient expression of the mutant CCDC6 T434A counteracted the ROS production, compared to the control (\# p $\leq 0.05$ ) (Figure 2G).

\section{CCDC6 and DDR protein expression in testicular seminomas}

In order to assess the CCDC6 expression in human testes and testicular germ cell tumors, in the first instance we tested twenty testicular seminomas, including IGCNU, one yolk salk tumor and five embrionary carcinomas and the corresponding normal tissues for CCDC6 expression by immunohistochemistry with an anti-CCDC6 specific monoclonal antibody. The representative immunohistochemical stainings are shown in Figure 3. CCDC6 was 
virtually undetectable $(<2.0 \%$ of cells) in the nuclei of the neoplastic cells in the seminomas. In the testicular tissues adjacent to the tumour, normal or atrophic and not affected by neoplastic transformation, it was possible to appreciate the CCDC6 positivity mainly in the nucleus of the spermatogonial cells identified, on the basis of the morphological features, at the basal layer of the tubules. The CCDC6 staining decreased proceeding from the basal layer to the lumen (Figure 3). The Sertoli and Leydig cells showed both cytosolic and nuclear staining. IGCNU was appreciable in nearly all tumour samples (90\%). In all these cases, the neoplastic cells present in the IGCNU showed weak $(<3 \%)$ CCDC6 nuclear stainings similar to normal spermatogonial cells (Figure 3 , middle). In the yolk salk tumor and in the embrionary carcinomas the immunostaining for CCDC6 was nearly undetectable (Figure 3, bottom).

In order to evaluate the activation of the DDR machinery in the same set of samples, we investigated the immunostaining for pS1981_ATM, the activated form of a key upstream regulator that controls most DDR events; the staining for pT68_Chk2, a central mediator of DDR that resulted barely detectable in IGCNU and in primary tumours was also analysed (Figure 4). Histone H2AX phosphorylation, a downstream chromatin modification linked to the generation of double-strand breaks (DSDS), showed a certain grade of positivity in normal gep. el ' (Figure 4). Such positivity for histone phosphoryla, visible also in some of the testicular semino analysec, was likely to be due to replicative stres in the vermatocyte population in the different $\mathrm{p}$ /ases of diffy ientiation present in the tumour and ealthy jissues, as already reported [8]. At the end, we c ked the expression of MDC1, recently emerge an important spatiotemporal regulator of the genorne in ority maintenance close to the top of the machinery signaling and lesion proceeding case of 561 An aberrant reduction or a lack of MD $\mathbf{A}$ ha een reported in a significant proportion of a inomas, upporting its candidacy as a tumor suppressor In contrast to carcinomas, almost no activetion or loss, nas been found in testicular germ cell tum [27] We also found no substantial variation in exp vo of MDC1 among our cases: a definite icle stain ng for MDC1 was in fact present in the nor$\mathrm{m}$ Semmiferous tubules (Figure 4), as reported [28], in the 1 NU (middle part of Figure 4) and in the invasive seminomas. Next, we confirmed all the observations we obtained by IHC staining also by Western blot analysis of 10 primary tissues obtained from a different set of patients. As shown in the representative samples of Figure 5, CCDC6 was expressed at very low levels in almost all seminomas and was virtually absent in teratocarcinomas and in embryonal carcinomas, compared to the normal samples (Figure 5). Moreover, we investigated the

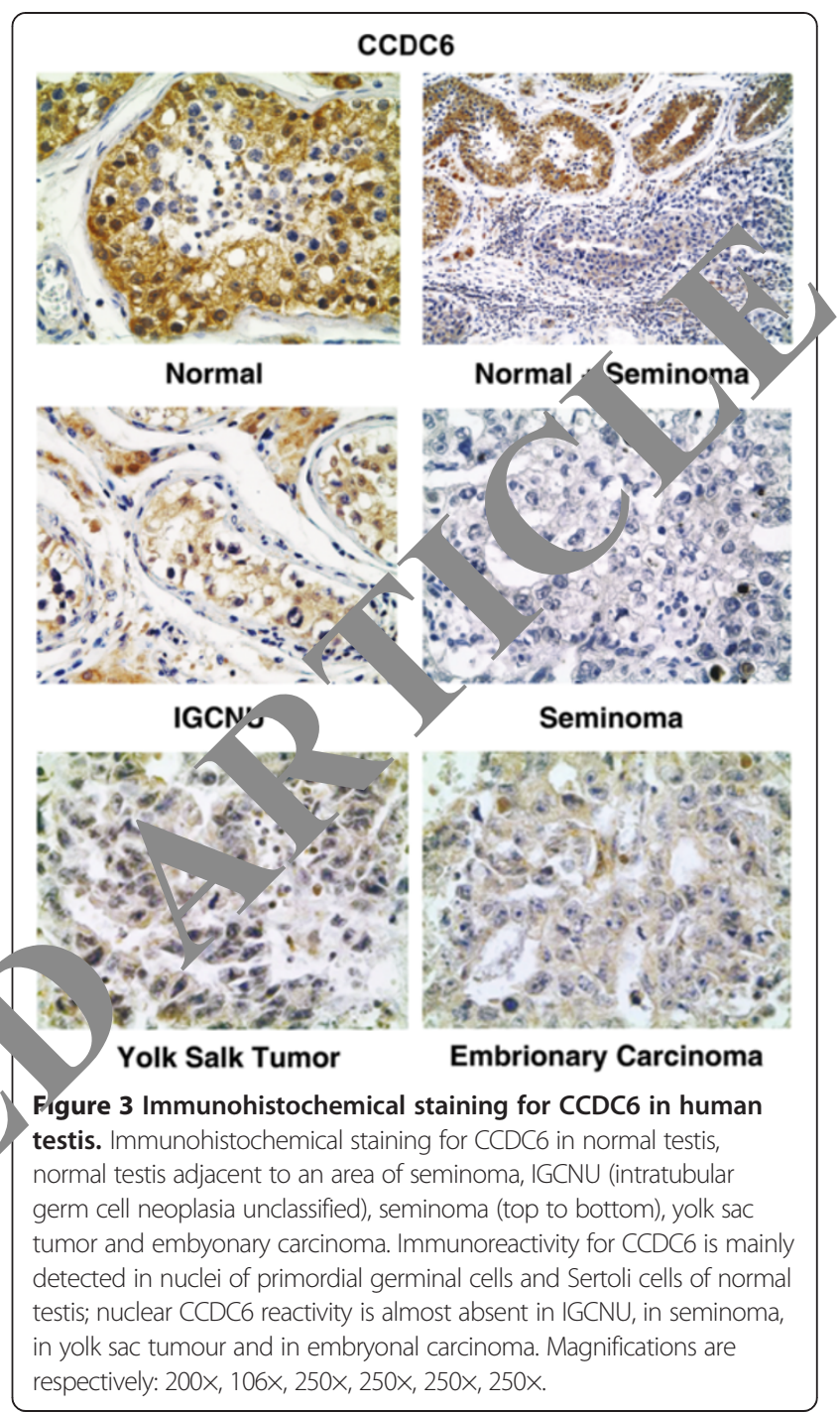

CCDC6 protein expression in the TCam-2 cell line, derived from a human seminoma. By immunoblot analysis, protein hybridization showed a low expression of CCDC6 in the TCam2 seminoma cells, similar to the primary tumours (Figure 5A). Quantitative real time PCR analysis showed low levels of transcripts for CCDC6 in these cells, compared to the expression levels detected in the $\mathrm{GC1}$ cells (Figure 5B), suggesting that the loss of CCDC6 in the neoplastic seminoma cells might not be dependent on a post-transcriptional mechanism. Next, in order to investigate the level of activation of the DDR molecules in the seminoma TCam2 cells, we performed Western Blot hybridization with specific antibodies against pS1981_ATM (pATM), pT68_Chk2 (pChk2) and pS139_H2AX ( $\gamma \mathrm{H} 2 \mathrm{AX})$ observing a barely detectable signal, after 1 hour treatment with $10 \mu \mathrm{M}$ H2O2 for all these DDR activation markers in TCam2 cells, compared to the levels observed in the GC1 normal testicular germ cells [18] (Figure 5C). 


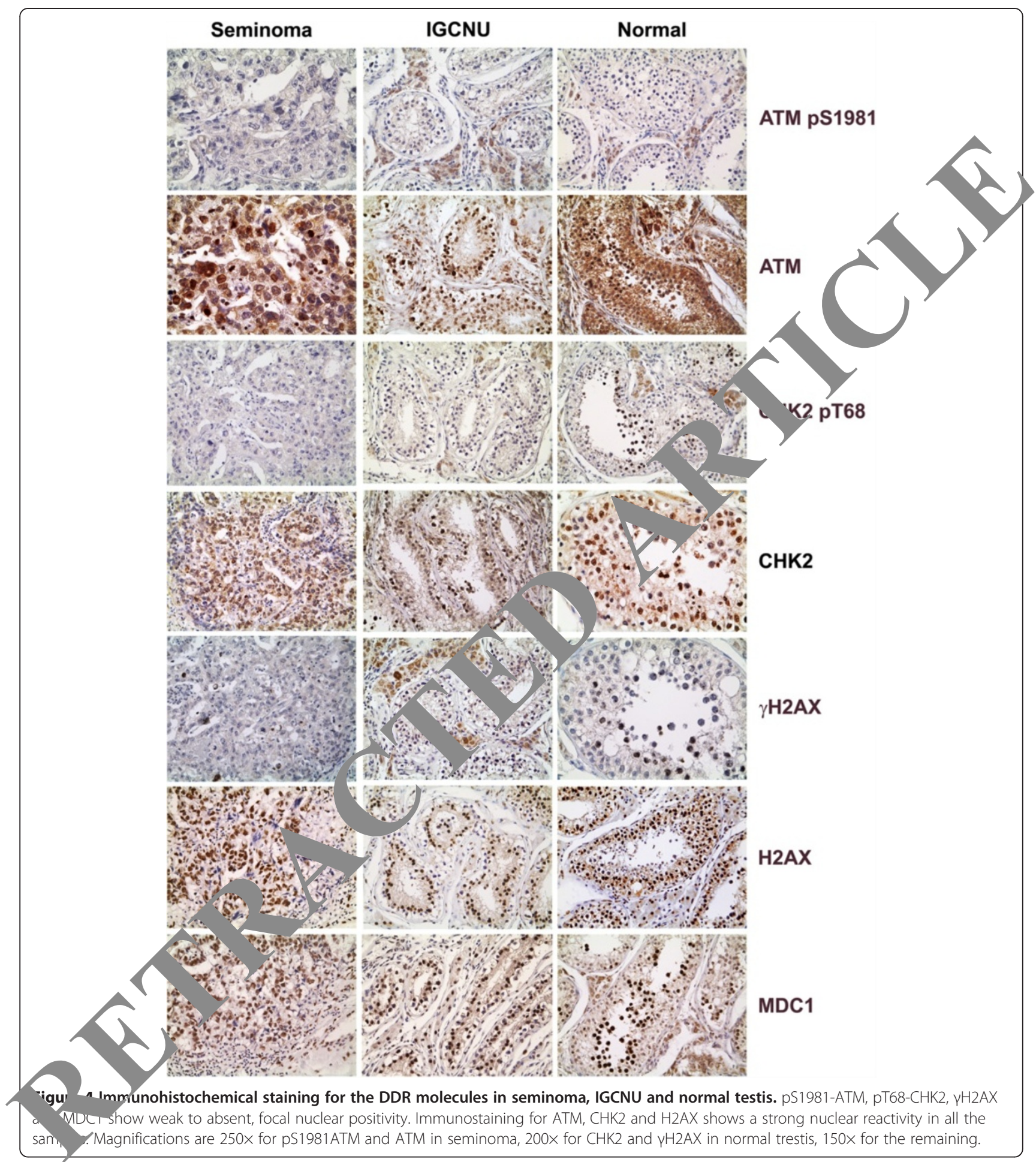

\section{TMA based analysis of CCDC6 expression in testicular} tumors

To confirm our findings and in order to extend the CCDC6 expression analysis in a larger set of human testicular samples, we took advantage of the tissue microarray (TMA) technique. TMA is a reliable and representative technology that allows the in situ analysis of tumoural and normal tissue samples in a high-throughput and internally controlled format. We screened a total of 87 human testicular tumours of different histotypes and 10 paired normal tissues using TMA. In Table 1, the TMA composition of the tumours derived from the testicular germ cells is listed. The CCDC6 protein expression was reduced in the tumours as witnessed by the low signal obtained per single 


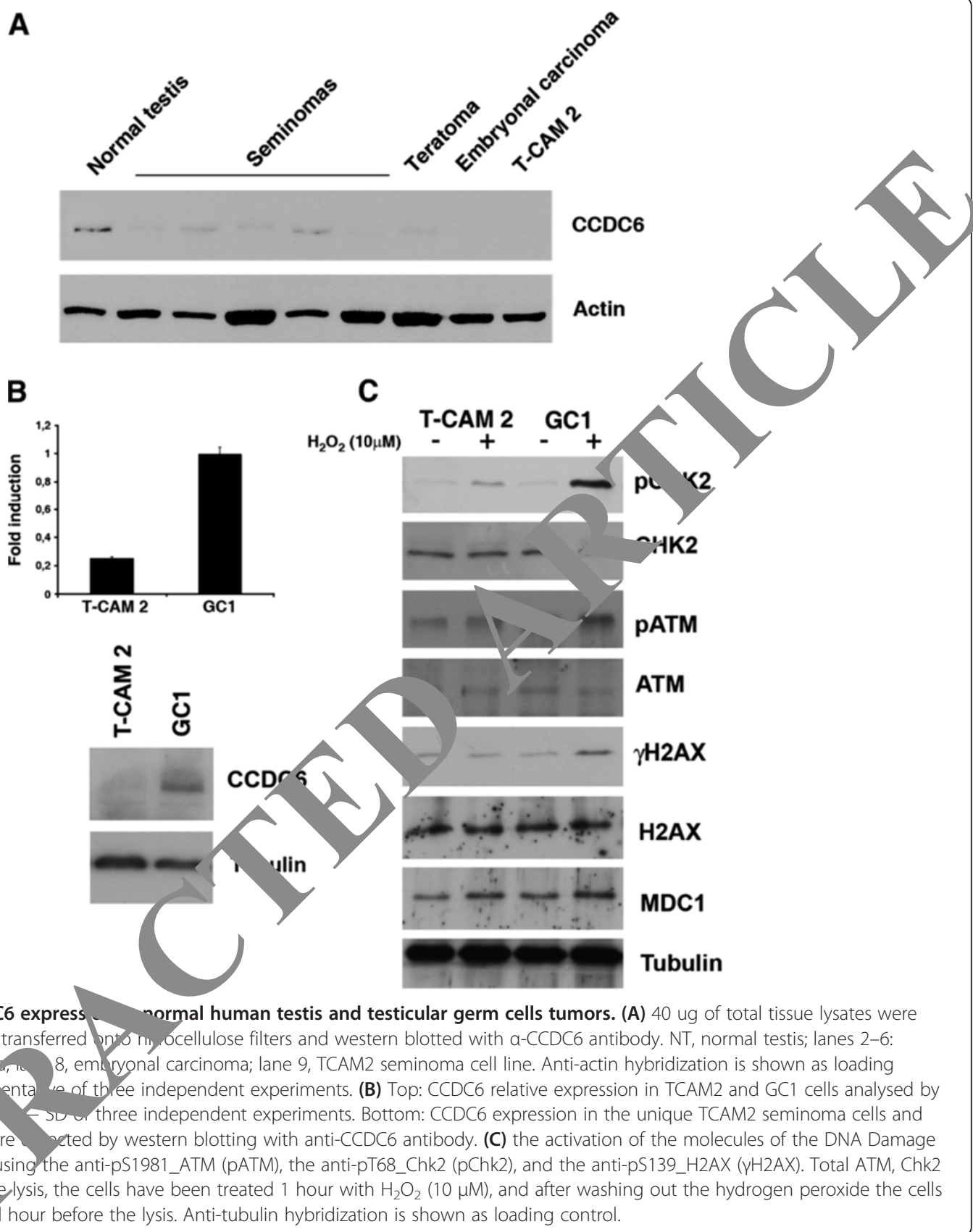

Ills ad by the decreased number of cells/field stained w. the arti-CCDC6 antibody.

In the testicular seminomas and embryonal carcinomas, we observed a low to absent nuclear positivity for CCDC6 (Figure 4). Together with the CCDC6 protein, we also assessed the engagement of the DDR machinery in the same tumours and in their normal counterparts, when available. Specifically, we investigated the DDRsignaling cascade at three nodal points: pS1981_ATM, the activated form of a key upstream regulator that controls most DDR events; pT68_Chk2, a central mediator of DDR and pS139_H2AX, the chromatin event following DSBs. By these markers we observed that DDR machinery activation resulted virtually absent in the human testicular tumours analyzed: little evidences of the activated checkpoint kinases ATM or Chk2 was indeed observed (data not shown), in contrast to some cells that showed activated pS139_H2AX (Table 1).

\section{Discussion}

The incidence of testicular germ-cell cancer, the most common malignancy in young men, has recently shown 
an alarming rise in the industrialized countries. This trend, together with the worrying decline in male reproductive health, and the fascinating biology of the germ cells and germ-cell tumours (GCTs), have stimulated an increasing number of studies to better understand the cellular and molecular biology of reproductions, and the molecular pathogenesis of testicular cancer [29-32].

The genome locus for CCDC6 is commonly rearranged in various tumours and, despite the emerging role for CCDC6 as a tumour suppressor, possibly controlling intra S-phase [33] and G2/M cell cycle checkpoints and DNA repair [11], its biology and pathology remain largely unexplored. A few CCDC6 somatic mutations have been reported in some tumours (www.sanger.ac.uk/genetics/ CGP/cosmic), but they are still in need of characterization. Also, there are no data on the abundance, localization or cell-type specificity of the CCDC6 protein in human tissues and tumours. The reasons which led us to choose spermatogenesis and testicular cancer to study CCDC6 include: (i) that CCDC6 is predicted as downregulated in germ cell tumours (by the analysis of the ArrayExpress Archive database), (ii) the occurrence, in the same tissue, of both mitotic and meiotic cell cycles, (iii) the high frequency of programmed DSBs as an essential part of genetic recombination during meiosis and (iv) the oxidative DNA damage envisaged as emerging mechanism of car cinogenesis in this tissue $[5,34]$.

For the purpose of assessing CCDC6 expression large series of human testicular tumour $\mathrm{s}$ ples, w analysed 20 primary tumours by also taking adv. nge of the TMA technique, that provides a $g$ eat opportu, ity to easily analyze, store and share IHC da of a large number of samples [35-37]. Primary tumours a TM A immunostaining investigations of $\mathrm{CO} \mathrm{C} 6$ expression demonstrated that CCDC6 is severely do gulated in all the different testicular tum analyed. Moreover, the analysis of IGCNU, the asu ne nyecursor lesion of germ cell tumours, shoved a vely detectable nuclear staining for CCDC6, sys ting tha CCDC6 loss might represent an early even du cancer development in the testis. Still, the observation y, at there is no significant difference

Table Gern Lell tumors TMA composition

\begin{tabular}{ccccccc} 
totypes & $\begin{array}{c}\text { Total number } \\
(\mathbf{8 7 )}\end{array}$ & $\begin{array}{c}\text { Percentage } \\
\%\end{array}$ & CCDC6 & & pH2AX \\
\hline Sç, minoma & 46 & 53 & $39 / 46$ & - & $+/-$ \\
& & & $7 / 46$ & $+/-$ & - \\
Embryonal carcinoma & 15 & 17,1 & $15 / 15$ & - & $+/-$ \\
Mixed carcinoma & 20 & 23 & $20 / 20$ & $+/-$ & $+/-$ \\
Teratoma & 5 & 5,8 & $2 / 5$ & $+/-$ & $+/-$ \\
& & & $3 / 5$ & - & - \\
Yolk sac tumor & 1 & 1,1 & $1 / 1$ & - & $+/-$ \\
\hline
\end{tabular}

in CCDC6 at mRNA and protein levels in the unique seminoma TCAM2 cell line reinforces the hypothesis that the loss of CCDC6 expression might occur as a transcriptional event. Since no fusions or mutations involving CCDC6 have been reported in testicular cancer, so far, we cannot rule out the existence of other mechanisms such as promoter methylation that could contribute inactivate CCDC6 in TGCTs. Nevertheless, we can ass in different tissues, other than the testis, ECDC6 m inactivated or lost by different mechanis such aे posttranslational modifications, and also at diffe t clages of tumour development, initiation or rogression. rurther investigations are in progress in diff nt tum our histotypes in order to clarify these critica

By analyzing the mur ne test ar cell population by IHC and by cell pop a specific expression of $C C D$ in the spermatogonial cells. In contrast, $\mathrm{CCF}$ Co as weaky expressed or undetectable in the spermato cerent stages of meiosis, and virtually negative in ast-meiotic stages of spermatogenesis. The assiveny decreasing levels of CCDC6 during the spermatocy $\mathrm{c}_{1}$, differentiation process could reflect the different levels of control needed for the mitotically prolifera testicular cells rather than during meiotic recombinat $\mathrm{n}$ where CCDC6 could probably induce inadequate a. osis and undermine spermatogenesis.

$\mathrm{NA}$ damage response is emerging as a physiological anti-cancer barrier in early stages of cancer development in several types of solid cancer, derived from somatic cells, as opposed to the exceptional paucity of such constitutive activation in human testicular germ cell tumours (TGCTs) [8]. Indeed, we detected low levels of CCDC6 and confirmed a very low activation of DDR-controlling molecules in the testicular germ cells tumours that we analyzed.

Interestingly, complex anti-oxidant defense systems have been reported in rat and human testes [34,38], while oxidative DNA damage is emerging as a mechanism of carcinogenesis [5,39]. Several studies have, in fact, also documented the presence of high levels of oxidative damage in A-T patients [40]. Recently, the ATM kinase has been reported to promote anti-oxidant defense and DNA repair, and, consequently, has been involved in response to oxidative stress [41].

It has been reported that, in primary testicular germ cells, the treatment with low doses of $\mathrm{H}_{2} \mathrm{O}_{2}$ is associated with a rise in oxidative stress and an induction of apoptosis [24]. $\mathrm{H}_{2} \mathrm{O}_{2}$ is a by-product of the cell metabolism and its cellular levels and maintenance are constantly under homeostatic regulation. As the major pathway of cell removal from the testis is through apoptosis, it is reasonable to assume that the redox status may either trigger or block the apoptotic death program depending on the severity of the oxidative stress. In this study, we first demonstrated that treatment of the GC1 cells with low doses 
of $\mathrm{H}_{2} \mathrm{O}_{2}$ induced apoptosis. Moreover, we found that, upon $\mathrm{H}_{2} \mathrm{O}_{2}$ treatment, the silencing of CCDC6 or the mutation in the recognition site for the ATM kinase in primary GC1 germ cells increases the rate of survival, impairs the phosphorylation of histone H2AX on S139, affects ROS production and makes the cells more resistant to oxidative damage. Since we have previously reported that $\mathrm{CCDC} 6$ could be considered a stress response protein participating to the control of genome stability [11], we can hypothesize that CCDC6 loss or impairment could also represent a mechanism to protect the cells from oxidative stress [9].

\section{Conclusions}

In conclusion, our results suggest that the loss of CCDC6 in tumour testes could represent a specific event that helps testicular germ cell tumours formation. Moreover, defects in the DDR machinery could account for the beneficial effects of radio and/or chemo-therapy in association with surgical treatment in these tumours. However, we believe that a recurrence of the disease, even at low frequency, could be generated by a sub-population of tumor germ cells still able to activate the DDR. Therefore, we hypothesize that CCDC6 usage as a marker of cell population resistance could eventually favour a personalized treatment choice.

\section{Additional files}

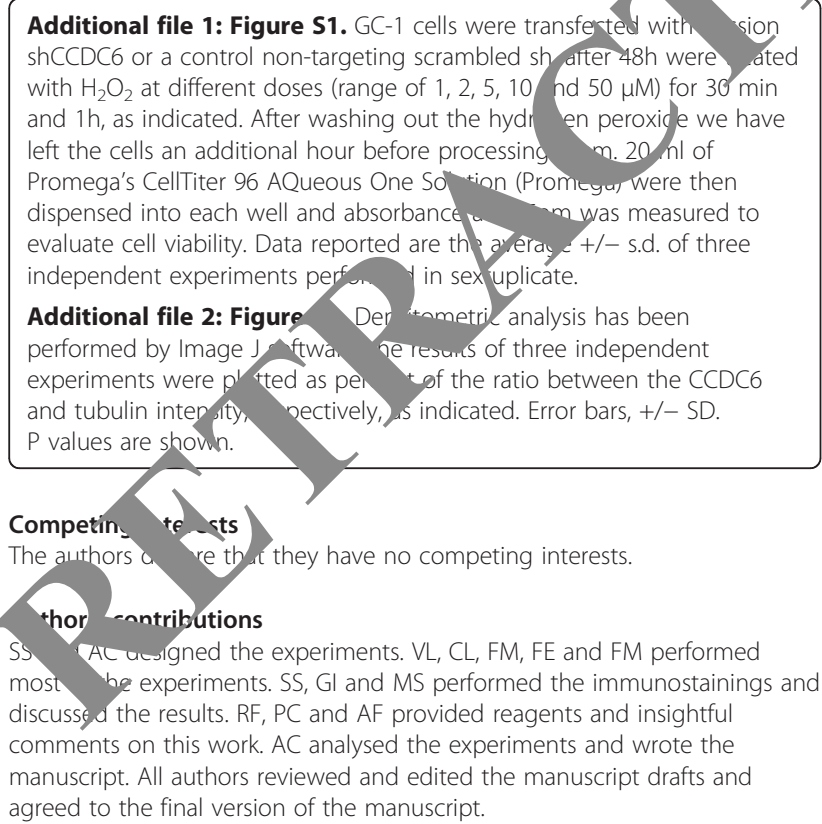

\section{Acknowledgements}

This work was supported by the Associazione Italiana Ricerca sul Cancro (AIRC n. 4952 to AC), by POR Campania FSE 2007/2013 "CREME Campania Research In Experimental Medicine", to CNR-IEOS-UOS Napoli and by the "Ministero dell'Istruzione, dell'Università e della Ricerca" (MIUR) (PRIN 20072JHN5W_003 to AC). We kindly acknolwledge Professor Giancarlo
Vecchio for his encouragement and support. We are grateful to Dr Mario Chiariello and to Dr Aniello Cerrato for critical reading of the manuscript and for helpful discussion. We thank Mario Berardone for artwork. Angela Celetti is grateful to CNR for the Short Term Mobility Award in 2009.

\section{Author details}

${ }^{1}$ Istituto di Endocrinologia ed Oncologia Sperimentale, CNRz, via S Pansini, 5, Naples 80131, Italy. ²Dipartimento di Medicina Molecolare e Biotecr orugie Mediche, Università Federico II, Naples, Italy. ${ }^{3}$ Dipartimento di Sci ఛze Biomediche Avanzate, Università Federico II, Naples, Italy. ${ }^{4}$ ISNF Naples, Italy. ${ }^{5}$ Dipartimento di Psicologia, Seconda Università di Nape Caserta 81100 , Italy.

Received: 18 April 2013 Accepted: 17 Septemben 213

Published: 24 September 2013

\section{References}

1. Oosterhuis JW, Looijenga LH: Terticulc orm-cent tumors in a broader perspective. Nat Rev Cancer 2 05, 5:210-

2. Chieffi P: Molecular target 1 he treatme, $r$ of testicular germ cell tumors. Mini-Rev Med Cha m 200 755-759.

3. Chieffi P, Franco R, P - alla G: Mole and cell biology of testicular tumors. Int Rev C Al Mo jol 2009, 278:277-308.

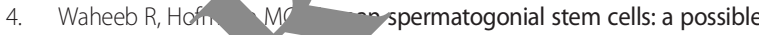
origin for spermat ic semınoma. Int J Androl 2011, 34(4 Pt 2):e296-e305.

5. Liu J, Q $\cup W$, Kadiiska oble of oxidative stress in cadmium toxicity and carcinog ToxicolAppl Pharmacol 2009, 238:209-214.

6. Bartkova J, Bak itm, Jajpert-De Meyts E, Skakkebaek NE, Sehested M, et al: ATM activa ion in normal human tissues and testicular cancer. Cell Cycle $2005,4: 838-15$

7. goulis VG, Vassiliou LV, Karakaidos P, Zacharatos P, Kotsinas A, et al: A ation of the DNA damage checkpoint and genomic instability in hu ian precancerous lesions. Nature 2005, 434:907-913. artkova J, Rajpert-De Meyts E, Skakkebaek NE, Lukas J, Bartek J, et al: DNA damage response in human testes and testicular germ cell tumours: biology and implications for therapy. Int J Androl 2007, 30:282-291. Celetti A, Cerrato A, Merolla F, Vitagliano D, Vecchio G, et al: H4(D10S170), a gene frequently rearranged with RET in papillary thyroid carcinomas: functional characterization. Oncogene 2004, 23:109-121.

10. Merolla F, Pentimalli F, Pacelli R, Vecchio G, Fusco A, et al: Involvement of $\mathrm{H} 4(\mathrm{D} 10 \mathrm{~S} 170)$ protein in ATM-dependent response to DNA damage. Oncogene 2007, 26:6167-6175.

11. Merolla F, Luise C, Muller MT Pacelli R, Fusco A, et al: Loss of CCDC6, the first identified RET partner gene, affects pH2AX S139 levels and accelerates mitotic entry upon DNA damage. PLOS ONE 2012, 7(5). e36177.doi:10.1371/journal.pone.0036177

12. Grieco M, Santoro M, Berlingieri MT, Melillo RM, Donghi R, et al: PTC is a novel rearranged form of the RET proto-oncogene and is frequently detected in vivo in human thyroid papillary carcinomas. Cell 1990, 60:557-563.

13. Takeuchi $K$, Soda M, Togashi Y, Suzuki R, Sakata S, et al: RET, ROS1 and ALK fusions in lung cancer. Nat Med 2012, 18:378-381.

14. Schwaller J, Anastasiadou E, Cain D, Kutok J, Wojiski S, et al: H4(D10S170), a gene frequently rearranged in papillary thyroid carcinoma, is fused to the platelet-derived growth factor receptor beta gene in atypical chronic myeloid leukemia with $\mathrm{t}(5 ; 10)(\mathrm{q} 33 ; \mathrm{q} 22)$. Blood 2001, 97:3910-3918.

15. Kulkarni S, Heath C, Parker S, Chase A, lqbal S, et al: Fusion of H4/D10S170 to the platelet-derived growth factor receptor beta in BCR-ABL-negative myeloproliferative disorders with a $t(5 ; 10)(q 33 ; q 21)$. Cancer Res 2000, 60:3592-3598

16. Puxeddu E, Knauf JA, Sartor MA, Medvedovic M, Moretti S, et al: RET/ PTC induced gene expression in thyroid PCCL3 cells reveals early activation of genes involved in regulation of the immune response. Endocr Relat Cancer 2005, 12:319-313

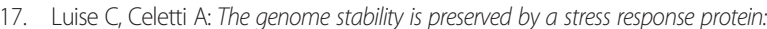
CCDC6. Germany: Lamberth Academic Publication; 2012. ISBN 978-3-659-14353-3.

18. Hofmann MC, Narisava S, Hess RA, Millán JL: Immortalization of germ cells and somatic testicular cells using the SV40 large T antigen. Exp Cell Res 1992, 201:417-435.

19. Mizuno Y, Gotoh A, Kamidono S, Kitazawa S: Establishment and characterization of a new human testicular germ cell tumor cell line TCam-2. Nippon Hinyokika Gakkai Zasshi 1993, 84:1211-1218. 
20. Rossi P, Dolci S, Albanesi C, Grimaldi P, Ricca R, et al: Follicle stimulating hormone induction of steel factor (SLF) mRNA in mouse Sertoli cells and stimulation of DNA synthesis in spermatogonia by soluble SLF. Dev Biol 1993, 155:68-74

21. Fedele M, Franco R, Salvatore G, Paronetto MP, Barbagallo F, et al: PATZ1 gene has a critical role in the spermatogenesis and testicular tumours. J Pathol 2008, 215:39-47.

22. Esposito F, Boscia F, Franco R, Tornincasa M, Fusco A, et al: Downregulation of estrogen receptor- $\beta$ associates with transcriptional coregulator PATZ1 delocalization in human testicular seminomas. J Pathol 2011, 224:110-120.

23. De Martino I, Visone $R$, Wierinckx A, Palmieri D, Ferraro A, et al: HMGA proteins up-regulate CCNB2 gene in mouse and human pituitary adenomas. Cancer Res 2009, 69:1844-1850.

24. Maheshwari A, Misro MM, Aggarwal A, Sharma RK, Nandan D: Pathways involved in testicular germ cell apoptosis induced by $\mathrm{H} 2 \mathrm{O} 2$ in vitro. FEBS / 2009, 276:870-881.

25. Hengartner MO: The biochemistry of apoptosis. Nature 2000, 407:770-776.

26. Stucki M, Jackson SP: gammaH2AX and MDC1: anchoring the DNAdamage-response machinery to broken chromosomes. DNA Repair 2006 5:534-543.

27. Bartkova J, Horejsí Z, Sehested M, Nesland JM, Rajpert-De Meyts E, et al: DNA damage response mediators MDC1 and 53BP1: constitutive activation and aberrant loss in breast and lung cancer, but not in testicular germ cell tumours. Oncogene 2007, 26:7414-7422.

28. Bartek J, Lukas C, Lukas J: Checking on DNA damage in S phase. Nat Rev Mol Cell Biol 2004, 5:792-804.

29. Andrews PW: Teratocarcinomas and human embryology: pluripotent human EC cell lines. Review article. APMIS 1998, 106:158-167.

30. Dieckmann K-P, Skakkebñk NE: Carcinoma in situ of the testis: review of biological and clinical features. Int J Cancer 1999, 83:815-822.

31. Grigor KM, Wylie CC: The origin and biology of CIS cells: general discussion. APMIS 1998, 106:221-224.

32. Skakkebaẽk NE, Berthelsen JG, Giwercman A, Müller J: Carcinoma-in-sit. the testis: possible origin from gonocytes and precursor of all tyr ss of germ cell tumours except spermatocytoma. Int J Androl 1987, 10:

33. Thanasopoulou A, Stravopodis DJ, Dimas KS, Schwaller J, Anas astadou Loss of CCDC6 affects cell cycle through impaired intra-r ase checkpoint control. PLoS One 2012, 7:e31007. Epub 201 Feb

34. Bauché F, Fouchard $M H$, Jégou B: Antioxidant systen in rat tes FEBS Lett 1994, 349:392-396.

35. Wan WH, Fortuna MB, Furmanski P: A rapid anc fficient method for testing immunohistochemical reactivity of mo Jonal ant bodies against multiple tissue samples simultaneously. of Methods 1987, 103:121-129.

36. Kononen J, Bubendorf L, KallioniemiA BM, So, Y, et al: Tissue microarrays for high-throughnut molectlar proiling of tumor specimens. Nat Med 1998 4:84

37. Mascolo M, llardi G, Mere Ru Veechione ML, et al: Tissue Microarray-Based Ey watio Chromatin Assembly Factor-1 (CAF-1)/ p60 as Tumour P qnostic Ma Ant J Mol Sci 2012, 13:11044-11062.

38. Hsia KT, Millar $\bigwedge \mathbb{R}, \quad S$, Selfridge J, Redhead NJ, et al: DNA repair gene Ercc1 is essential for nal spermatogenesis and oogenesis and for function al integrity of gy $n$ cell DNA in the mouse. Development 2003, $130: 378$

39. Viscont rieco $D$ New insights on oxidative stress in cancer. Curr Opin Disco vel 2009, 12:240-245.

Ru b I, Cose, uno C, Del Giudice E, Broccoletti T, Amorosi S, et al: In ataxiate' asia betamethasone response is inversely correlated to rebellar atrophy and directly to antioxidative capacity. Eur J Neurol 2. 16:755-759.

41. Cosentino C, Grieco D, Costanzo V: ATM activates the pentose phosphate pathway promoting anti-oxidant defence and DNA repair. EMBO J 2011 , 30:546-555.

\section{doi:10.1186/1471-2407-13-433}

Cite this article as: Staibano et al:: Critical role of CCDC6 in the neoplastic growth of testicular germ cell tumors. BMC Cancer 2013 13:433.

\section{Submit your next manuscript to BioMed Central and take full advantage of:}

- Convenient online submission

- Thorough peer review

- No space constraints or color figure charges

- Immediate publication on acceptance

- Inclusion in PubMed, CAS, Scopus and Google Scholar

- Research which is freely available for redistribution 